\title{
Evaluating the Depth of the Epidural Space with the Use of Ultrasound
}

\author{
Pablo Escovedo Helayel, TSA ${ }^{1}$, Diogo Bruggemann da Conceição, TSA 2, Gustavo Meurer ${ }^{3}$, \\ Claudia Swarovsky ${ }^{3}$, Getúlio Rodrigues de Oliveira Filho, TSA ${ }^{4}$
}

\begin{abstract}
Summary: Helayel PE, Conceição DB, Meurer G, Swarovsky C, Oliveira Filho GR - Evaluating the Depth of the Epidural Space with the Use of Ultrasound.
\end{abstract}

Background and objectives: The objective of the present study was to evaluate the use of the ultrasound on the determination of the depth of the epidural space.

\begin{abstract}
Methods: Sixty patients were included in this prospective study; the $L_{3}-L_{4}$ space was initially identified by palpation followed by the ultrasound measuring the depth of the epidural space (PU). After the epidural puncture the measurements o the depth (PA) were recorded. The data underwent descriptive statistics, and the concordance correlation coefficient and Bland-Altman analysis, with $95 \%$ confidence interval were calculated.
\end{abstract}

Results: Analysis of concordance between the palpation and ultrasound methods was $86.6 \%$. Mean values of PU obtained were $4.97 \pm 0.51 \mathrm{~cm}$ and PA $4.97 \pm 0.71 \mathrm{~cm}$, and Pearson correlation coefficient of 0.66 while Bland-Altman analysis revealed a mean difference of $0.0035 \pm 0.53 \mathrm{~cm}$ with $95 \%$ confidence interval between -0.228 and 0.221 .

Conclusions: The ultrasound is a precise tool to determine the depth of the epidural space.

Keywords: ANESTHETIC TECHNIQUES, Regional: epidural; EQUIPMENT, Ultrasound; METHODOLOGY: validation studies.

[Rev Bras Anestesiol 2010;60(4): 376-382] @Elsevier Editora Ltda.

\section{INTRODUCTION}

The high variability of the distance between the skin and the epidural space and its surface anatomical references hinder its correct identification ${ }^{1,2}$ demanding care when positioning the patient and technical experience that could affect the success rate of epidural blocks ${ }^{3-6}$. The depth of the epidural space depends on the trajectory of the needle. Several attempts to relate this depth with patient-related parameters, such as weight and height, proved ineffective for clinical use 7 . From 1980 on, a strong correlation between the depth of the epidural space visualized on ultrasound and the distance measured by the needle was observed ${ }^{8,9}$. Thus, the ultrasound has been considered a useful tool to identify the depth of the epidural space and its anatomical structures ${ }^{10,11}$.

Received from Hospital Governador Celso Ramos - CET/SBA aggregated of Secretaria de Estado da Saúde de Santa Catarina (SES-SC) and Núcleo de Ensino e Pesquisa em Anestesia Regional (NEPAR), Florianópolis, SC.

1. Anesthesiologist; Coordinator and Researcher of NEPAR, and Instructor Co-responsible for CET/SBA aggregated of SES-SC

2. Anesthesiologist; Researcher of NEPAR and Instructor Co-responsible for CET/SBA aggregated of SES-SC

3. Anesthesiology Resident

4. Anesthesiologist; PhD in Anesthesiology; Researcher of NEPAR and Responsible for CET/SBA aggregated of SES-SC

Submitted on January 8, 2010

Approved on March 1, 2010

Correspondence to:

Dr. Pablo Escovedo Helayel

Av. Governador Irineu Bornhausen, 3440/204

Agronômica

88025200 - Florianópolis, SC

E-mail:pehelayel@hotmail.com
The objective of the present study was to validate the use of the ultrasound as a tool to determine the depth of the epidural space as well as to evaluate its precision on identifying the $L_{3}-L_{4}$ intervertebral space.

\section{METHODS}

After approval by the Ethics on Research Committee of the Hospital Governador Celso Ramos and signing of the informed consent, 60 patients, physical status ASA I and II, ages between 18 and 65 years, scheduled for elective surgeries under epidural block in the field of general, urologic, vascular, and orthopedic surgeries were enrolled in this study. Patients with neurological diseases, history of spinal surgery, deformities of the spine, infection at the puncture site, coagulopathies, and any other contraindication to neuroaxis block were exclude from this study. The physical status (ASA), age, weight, height, and body mass index (BMI) of all patients were recorded.

All patients were monitored with cardioscope, pulse oximeter, and non-invasive blood pressure. A line was inserted with an $18 \mathrm{G}$ catheter for administration of midazolam IV $\left(0.05 \mathrm{mg}^{\mathrm{kg}}{ }^{-1}\right)$ 10 minutes before the blockade.

Patients were placed in the sitting position and the $L_{3}-L_{4}$ space was identified by palpation based on the Tuffier line (horizontal line between the iliac crests) and marked with a pen. This was followed by the ultrasound using a convex transducer of 2-5 MHz (Sonoace 8000SE ${ }^{\circledR}$, Medison, South Korea). Initially the intervertebral space determined by pal- 
pation was confirmed with the transducer on the longitudinal position identifying the sacrum when it was slowly moved to the cephalad direction until the $L_{4}-L_{4}$ space. Once the intervertebral space was identified, the transducer was moved $90^{\circ}$ to obtain the transverse position, and, inclining slightly on the cephalad or caudal direction to obtain a better image of the intervertebral space, which was frozen for the measurement of the depth of the epidural space (Figure 1). With the transducer on the same position the skin was marked with a pen on the center of the horizontal surface of the transducer (middle line), and another coinciding with the meddle point of the right lateral surface of the transducer ${ }^{11}$, the inclination angle in relation to the inferior apophysis was measured with the help of a protractor (Figure 2). The puncture site was determined by the intersection of both marks; the angle provided the inclination

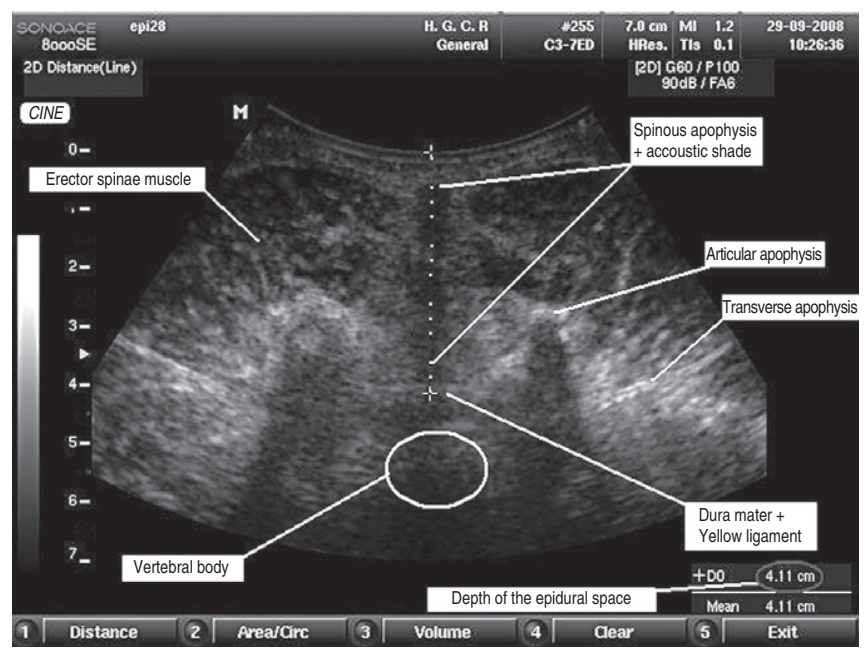

Figure 1 - Ultrasound of the $\mathrm{L}_{3}-\mathrm{L}_{4}$ Intervertebral Space on the Transversal Approach, Showing Structures of the Neuroaxis and Measurement of the Distance between the Skin until the Epidural Space in Centimeters.

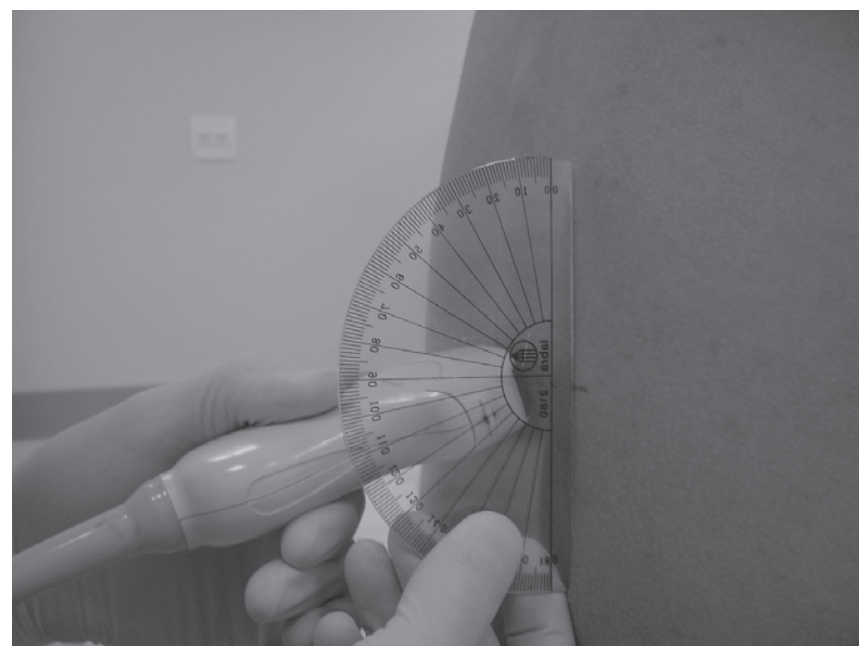

Figure 2 - Convex Transducer Positioned Transversally to the $\mathrm{L}_{3}$ $\mathrm{L}_{4}$ Intervertebral Space to Measure the Distance between the Skin and the Epidural Space and the Inclination Angle in Relation to the Inferior Apophysis with the Aid of a Sterile Protractor. of the needle in relation to the skin. The epidural block was performed maintaining the patient on the same position after antisepsis, placement of sterile surgical fields, and local anesthesia of the skin and deeper planes with $5 \mathrm{ml}$ of $1 \%$ lidocaine. A $17 \mathrm{G}$ Tuohy needle $(8.89 \mathrm{~cm})$ marked at $1-\mathrm{cm}$ intervals was inserted in a point and angulation determined previously, and it was redirected if necessary. The number of repositions (change in angle) and puncture attempts (different puncture area) were recorded. After identification of the epidural space by the loss of resistance technique with saline, the angulation of the needle in relation to the skin was determined by a sterile protractor (Figure 3) and the needle was marked close to the skin with a pen to measure the depth.

After collection of the data, the ultrasound images of the intervertebral spaces were stored for posterior evaluation by two investigators regarding the quality of the images of the following structures: spinous, transverse, and articular apophysis, posterior border of the vertebral body, and yellow ligament and dura-mater (visualized as a single line) similar to the description of other studies ${ }^{11}$. An independent evaluation was performed and the degree of concordance was determined.

Calculation of the sample size was based on the following parameters, according to previous findings ${ }^{3}$ : distance from the skin to the epidural space $=50.9 \pm 12 \mathrm{~mm}$, and depth of the epidural space $=6.9 \mathrm{~mm}$. This was considered the maximal accepted difference between the two measurements of this study. Thus, it was estimated that 60 patients would be necessary with a type I probability error of $5 \%$, and type II probability error of $10 \%$. Descriptive analysis of the data was undertaken using means and standard deviations, for continuous parameters, and percentages for nominal parameters. The Spearmen correlation coefficient was calculated to estimate the degree of concordance between both methods of evaluation, ultrasound depth of the epidural space (PU) versus the depth of the needle introduced until the epidural space (PA), and ultrasound angulation in relation to the skin (AU)

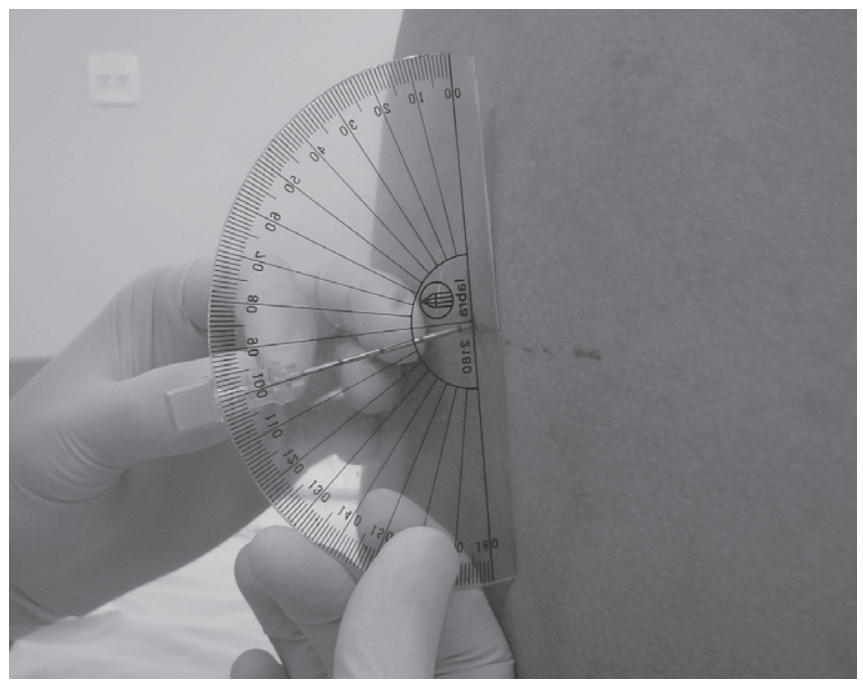

Figure 3 - Determination of the Angle of the Tuohy Needle in Relation to the Skin with a Sterile Protractor After Identification of the Epidural Space by the Loss of Resistance Technique. 
versus the angle of the needle in relation to the skin (AA). Concordance of both methods of measuring the depth of the epidural space was estimated by the Bland-Altman method 12. The remaining data related to patient characteristics were submitted to multiple linear regression in order to evaluate the possible significant association with the differences of depth and angulation.

\section{RESULTS}

Sixty patients with mean age of $45 \pm 14$ years, of which 41 (68\%) were males, participated in this study. They had a mean height of $167 \pm 8 \mathrm{~cm}$; mean weight of $71 \pm 12 \mathrm{~kg}$; and mean BMl $25 \pm$ $4 \mathrm{~kg} \cdot \mathrm{m}^{2}$. According to the criteria of the ASA, 29 (48\%) were classified as ASA I, 27 (45\%) as ASA II, and 4 (7\%) as ASA III. Considering the type of procedure, $27(45 \%)$ underwent vascular surgery, $22(37 \%)$, urologic surgery, $7(12 \%)$, general surgery, and $4(6 \%)$, orthopedic surgery.

Mean PU values were $4.97 \pm 0.51 \mathrm{~cm}$, and PA $4.97 \pm$ $0.71 \mathrm{~cm}$, with Pearson correlation coefficient of 0.66 , while Bland-Altman analysis revealed a mean difference of $0.0035 \pm$ $0.11 \mathrm{~cm}$, with $95 \%$ confidence limits between -0.228 and 0.221 (Chart 1). Mean AU values were $84.45 \pm 5.14^{\circ}$ and $A A$ $80.68 \pm 7.39^{\circ}$, with Pearson correlation coefficient of 0.41 , while Bland-Altman analysis revealed a mean difference of $3.76 \pm 1.15^{\circ}$, with a $95 \%$ confidence limit between 1.47 and 6.05. Repositioning of the needle did not show a correlation with the difference observed in the angles (Spearman coefficient of 0.043 and $p=0.74$ ). On multiple linear regression analysis, only the weight showed a significant association with the difference between measurements $(R$ coefficient $=0.3$ and $p=0.019$ ). However, only $9.1 \%$ variance in the differences among measurements was explained by weight variation, since the adjusted determination coefficient $\left(R^{2}\right)$ was 0.091 . Analysis of the concordance between the palpation and

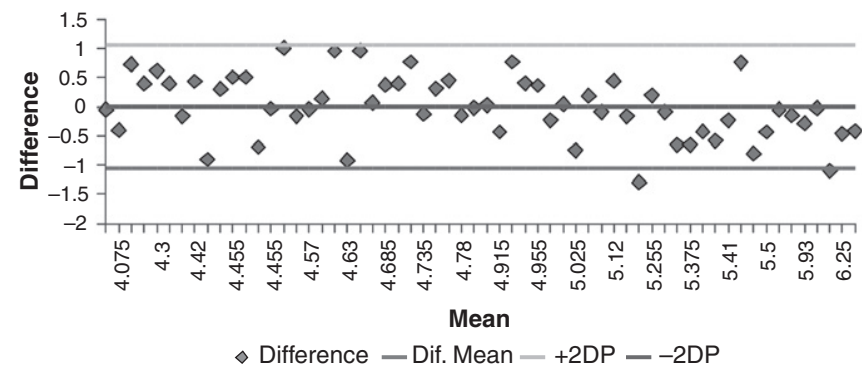

Chart 1 - Bland-Altman Chart of the Measurements of the Depth of the Epidural Space Determined by Ultrasound and by the Depth of Insertion of the Tuohy Needle. ultrasound methods on the identification of the $L_{3}-L_{4}$ space was $86.6 \%$. In all cases, only one puncture on the skin at the point determined previously was necessary, and, in 34 (55\%), redirection of the needle was not necessary. On the remaining cases, $1(14.5 \%)$ to $5(3.2 \%)$ changes in the angle of insertion of the needle were necessary.

\section{DISCUSSION}

This study showed a high correlation between the measurements of the distance between the skin and the epidural space by palpation and ultrasound. Similarly to other studies, the findings of the present study revealed that ultrasound is capable of generating a fairly precise estimate of the depth of the epidural space ${ }^{8,9}$.

As observed previously ${ }^{3,13}$, the depth of the epidural space had a close relationship with the weight and BMI of patients. The values of those variables observed in this study were comparable to those observed in previous studies $3,4,9$ done in patients with equally lower body mass index. The concordance between PU and PA was not affected by the BMI, which has also been demonstrated $11,13,14$. Besides estimating the depth the ultrasound can facilitate the epidural puncture before it is performed by evaluating the anatomy of the spine and providing greater accuracy on the identification of the site of puncture on the skin $7,15,16$. Only one attempt was necessary in all patients, and in $55 \%$ of the cases it was not necessary to redirect the needle. This indicates that the ultrasound can help define the best place of entry on the skin and the ideal direction of the needle. The usefulness of measuring the angle between the transducer and the skin to make the relationship PU/PA more precise and reduce the need of repositioning the needle did not show a good correlation with the difference observed among angles. Thus, the measurement of those angles does not seem to facilitate epidural punctures, it only increases the time of the ultrasound.

Identification of the $L_{3}-L_{4}$ space by palpation showed a high correlation with the ultrasound (86.6\%). Those levels of accuracy are much higher than those observed by other authors ${ }^{2}$, who reported accuracy lower than $30 \%$. Although this result shows a better identification of the $L_{3}-L_{4}$ space, it does not guarantee the correct position of the needle in the desired intervertebral space by palpation.

To conclude, the ultrasound is a precise tool to determine the depth of the epidural space. Besides, it facilitates epidural puncture by the correct identification of the intervertebral space and spinal anatomy; however, it does not exclude the need to use the loss of resistance technique. 


\section{REFERÊNCIAS / REFERENCES}

01. Furness G, Reilly MP, Kuchi S. An evaluation of ultrasound imaging for identification of lumbar intervertebral level. Anaesthesia, 2002;57:277280.

02. Broadbent C. Ability of anaesthetists to identify a marked lumbar interspace. Pain Practice, 2001;1:199.

03. Bevacqua BK, Haas T, Brand F. A clinical measure of the posterior epidural space depth. Reg Anesth, 1996;21:456-460.

04. Sutton DN, Linter SP. Depth of extradural space and dural puncture. Anaesthesia, 1991;46:97-98.

05. Hamza J, Benhamou D. Dural puncture and depth of the extradural space. Anaesthesia, 1992;47:169-170.

06. Oliveira Filho GR, Gomes HP, Fonseca MHZ et al. Predictors of successful neuraxial block: a prospective study. Eur J Anaesthesiol, 2002;19:447-451

07. Grau T, Leipold RW, Conradi R et al. Ultrasound control for presumed difficult epidural puncture. Acta Anaesthesiol Scand, 2001;45:766-771.

08. Cork RC, Kryc JJ, Vaughan RW. Ultrasonic localization of the lumbar epidural space. Anesthesiology, 1980; 52:513-516.

09. Currie JM. Measurement of the depth to the extradural space using ultrasound. Br J Anaesth, 1984;56:345-347.

10. Helayel PE, Conceição DB, Oliveira Filho GR. Bloqueios nervosos guiados por ultrassom. Rev Bras Anestesiol, 2007;57:106-123.

11. Arzola C, Davies S, Rofaeel A et al. Ultrasound using the transverse approach to the lumbar spine provides reliable landmarks for labor epidurals. Anesth Analg, 2007;104:1188-1192.

12. Bland JM, Altman DG. Measuring agreement in method comparison studies. Stat Methods Med Res, 1999;8:135-160.

13. Balki $M$, Lee $Y$, Halpern $S$ et al. Ultrasound imaging of the lumbar spine in the transverse plane: the correlation between estimated and actual depth to the epidural space in obese parturients. Anesth Analg, 2009;108:1876-1881.

14. Oliveira Filho GR, Boso AL, Benedetti RH. Distância da pele ao espaço subaracnoideo em pacientes geriátricos: comparação entre os acessos mediano e paramediano. Rev Bras Anestesiol, 1997;47:226-230.
15. Grau T, Leipold R, Conradi R et al. Ultraschall und Periduralanasthesie. Technische Moglichkeiten und Grenzen einer diagnostischen Untersuchung des Periduralraums. Anaesthesist, 2001;50:94-101.

16. Grau T, Leipold RW, Conradi $R$ et al. Ultrasound imaging facilitates localization of the epidural space during combined spinal and epidural anesthesia. Reg Anesth Pain Med, 2001;26:64-67.

Resumen: Helayel PE, Conceição DB, Meurer G, Swarovsky C, Oliveira Filho GR - Evaluación de la Profundidad del Espacio Epidural con el Uso del Ultrasonido.

Justificativa y objetivos: El objetivo de este estudio fue evaluar el uso del ultrasonido para la determinación de la profundidad del espacio epidural.

Método: Sesenta pacientes fueron ubicados, prospectivamente teniendo la identificación del espacio intervertebral $L_{3}-L_{4}$ inicialmente realizada por el método de palpación. Posteriormente se usó el método de ultrasonido, y se realizó la medida de la profundidad del espacio epidural (PU). Después de la punción epidural, se anotaron las medidas de la profundidad (PA). Se midieron las estadísticas descriptivas de los datos y se calculó el coeficiente de correlación de concordancia y análisis de Bland-Altman, con un intervalo de un $95 \%$ de confianza para las medidas de profundidad.

Resultados: El análisis de concordancia entre el método de palpación y el ultrasonido fue de un $86,6 \%$. Se obtuvieron valores promedios de PU 4,97 $\pm 0,51 \mathrm{~cm}$ y PA $4,97 \pm 0,71 \mathrm{~cm}$ y un coeficiente de correlación de Pearson de 0,66, mientras el análisis Bland-Altman arrojó una diferencia promedio de $0,0035 \pm 0,53 \mathrm{~cm}$, con un límite de un $95 \%$ de confianza entre $-0,228$ a 0,221 .

Conclusiones: El ultrasonido es un instrumento preciso para la determinación de la profundidad del espacio epidural. 